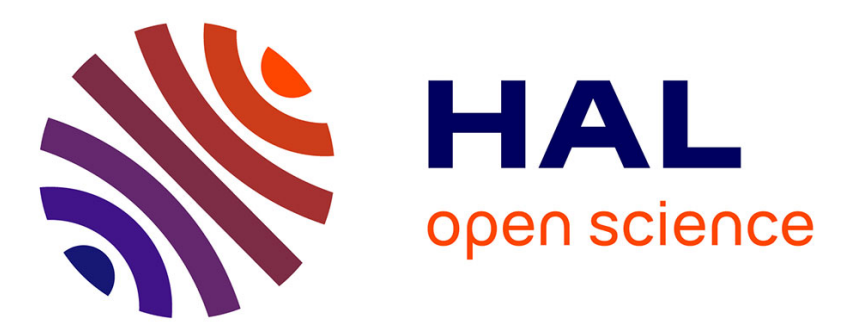

\title{
Mutual effect of groove size and anisotropy of cylinder liner honed textures on engine performances
}

\author{
Mohammed Yousfi, Sabeur Mezghani, Ibrahim Demirci, Mohammed El
}

Mansori

\section{- To cite this version:}

Mohammed Yousfi, Sabeur Mezghani, Ibrahim Demirci, Mohammed El Mansori. Mutual effect of groove size and anisotropy of cylinder liner honed textures on engine performances. Advanced Materials Research, 2014, 966-967, pp.175-183. 10.4028/www.scientific.net/AMR.966-967.175 . hal01178168

\section{HAL Id: hal-01178168 \\ https://hal.science/hal-01178168}

Submitted on 27 Aug 2015

HAL is a multi-disciplinary open access archive for the deposit and dissemination of scientific research documents, whether they are published or not. The documents may come from teaching and research institutions in France or abroad, or from public or private research centers.
L'archive ouverte pluridisciplinaire HAL, est destinée au dépôt et à la diffusion de documents scientifiques de niveau recherche, publiés ou non, émanant des établissements d'enseignement et de recherche français ou étrangers, des laboratoires publics ou privés. 


\title{
Mutual effect of groove size and anisotropy of cylinder liner honed textures on engine performances
}

\author{
M Yousfi ${ }^{1,2}$, S Mezghani $^{1}$, I Demirci ${ }^{1}$ and M El Mansori ${ }^{1}$ \\ ${ }^{1}$ Arts et Métiers ParisTech, Laboratory of Mechanics, Surface and Materials Processing (MSMP), \\ Rue Saint Dominique, Châlons-en-Champagne, France \\ ${ }^{2}$ Renault S.A.S., Powertrain Process Engineering Division, Rueil Malmaison, Paris, France \\ E-mail: mohammed.yousfi@ensam.eu
}

\begin{abstract}
The cylinder liner surface texture, widely generated by the honing technique, contributes a lot on engine functional performances (friction, oil consumption, running-in, wear etc.). In order to improve these functional performances, different honing processes are being developed. These different honing processes generate surfaces with various texture features characteristics (roughness, valleys depth, valley width, cross hatch angle, etc.). This paper addresses a comparison of ring-pack friction for cylinder texture with different cross-hatch angles and valley sizes. It takes in consideration the mutual effect of valley depth and honing angle. A numerical model is developed to predict friction within the cylinder ring-pack system in mixed lubrication regime and a morphological method is used to characterize groove depth. The results show the effect of different honing variables (rotation speed, stroke speed and indentation pressure) on cylinder bore surface textures and hydrodynamic friction of the ring-pack system.
\end{abstract}

\section{Introduction}

In the automotive industry, in order to respect environmental regulations, manufacturing engine with lower greenhouse gas emissions is a major objective. Cylinder liner texture has a high influence on friction losses and oil consumption in an engine [1], [2] and is generated by a finishing process called honing [3]. The honing process consists of two or three successive operations. The first stage, rough honing, allows improvement in the cylindricality of the bore using coarse abrasive stones. The subsequent stages generate the surface with the desired roughness and texture features (plateau and valley size, groove cross-hatch angle, etc.). The axial motion of the honing tool combined with rotation generates grooves with a specific cross-hatch angle.

Different honing techniques (plateau honing, helical slide honing, slide honing, etc.) are used in industry [4]. The main differences between the processes are generally due to roughness or/and cross-hatch angle [4], [5].

As shown in [1], friction in the piston ring-liner interface is increased with a higher average roughness of the cylinder liner surface. Mezghani et al [3], [6] demonstrated, in the case of plateau honing process, that texture with lower plateau roughness and valley depth contribute to reduce frictional performance of honed surfaces. Another influential parameter is the groove valley depth/width ratio which is generally equal or lower than $10 \%$ to reduce friction in lubricated contacts [7], [8].

Concerning the groove orientation, a study based on a numerical hydrodynamic contact model explained the choice of honing cross-hatch in some industrial processes [9]. It determined two optimal ranges of crosshatch angles $\left(40^{\circ}-60^{\circ}\right.$ and $\left.120^{\circ}-140^{\circ}\right)$ in hydrodynamic lubrication condition for lower friction performances. Nevertheless, other studies have shown good frictional behavior for low groove orientations $\left(15^{\circ}-25^{\circ}\right)$ [10], [9]. Moreover, according to [1], oil consumption is reduced with increasing cross-hatch angle of the cylinder liner texture.

In general, it was demonstrated in the literature that groove size and orientation are two influential texture features on engine functional performances (friction, lubrication, wear, etc.). However the mutual effect of both groove orientation and size on engine functionality is still unknown. 
In this paper, the mutual influence of honing angle and groove size was studied through honing experiments at different rotational and axial velocities and indentation conditions in order to generate textures that consist of grooves at different cross-hatch angles and sizes (depth and width). Then, frictional performance of the obtained textures were evaluated in order the establish a link between size, orientation of valleys and functionality. Finally, a comparative strategy concerning friction reduction in ring-pack system is discussed.

\section{Experimental procedure}

Honing experiments. In this study, instrumented honing experiments have been undertaken on a vertical honing machine with an expandable tool (NAGEL no. 28-8470) (Fig. 1). The considered part is a crankcase that consists of four lamellar grey cast iron cylinder liners. First, during the rough and finish stages, all of the process parameters are similar for all the honed bores. After these stages, the obtained texture consists of cross-hatched grooves with an angle of $50^{\circ}$. Then, in the third honing stage, different rotational and axial velocities were used to generate different groove orientations $\left(30,50,80,110\right.$ and $\left.130^{\circ}\right)$. Moreover, in this stage, two different expansion modes were used: an electromechanical and a hydraulic expansion. The details of the most important applied process condition are represented in Table 1.

a)

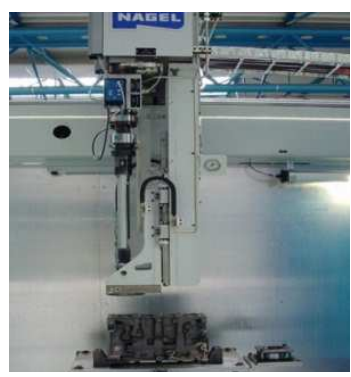

b)

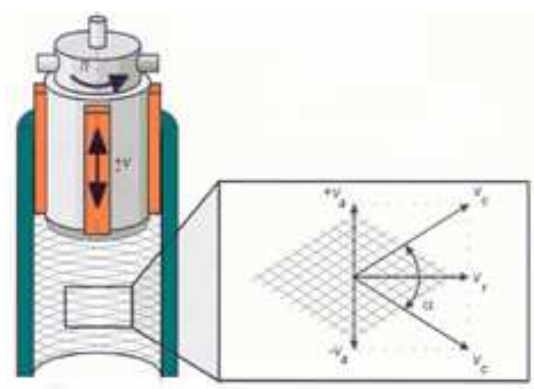

Fig. 1. (a)Vertical honing machine with an expansible tool ; (b) Schematic representation of a honing head and its motion.

Table 1. Honing operating condition in the second and third honing stages.

\begin{tabular}{lccc}
\hline \multirow{2}{*}{ Honing parameters } & Finish honing & \multicolumn{2}{c}{ Super-finish honing step } \\
\cline { 3 - 4 } & & $\begin{array}{c}\text { Mechanical expansion } \\
\text { (finish) }\end{array}$ & $\begin{array}{c}\text { Hydraulic expansion } \\
\text { (plateau) }\end{array}$ \\
\hline Axial speed $(\mathrm{m} / \mathrm{min})$ & 18 & $11,18,27,29$ & $11,18,27,29$ \\
Rotation speed $(\mathrm{rpm})$ & 160 & $58,85,135,160,170$ & $58,85,135,160,170$ \\
Honing duration $(\mathrm{sec})$ & 20 & 12 & 7 \\
Expansion type & Mechanical & Mechanical & Hydraulic \\
Expansion speed $(\mu \mathrm{m} / \mathrm{s})$ & $2-4$ & 1.7 & - \\
Contact pressure $(\mathrm{bar})$ & - & - & 6 \\
Number of stones & 6 & 6 & 6 \\
Abrasive grit type & Silicon Carbide & Silicon Carbide & Silicon Carbide \\
Grain size $(\mu \mathrm{m})$ & 107 & 107 & 30 \\
Bond type & Vitrified & Vitrified & Vitrified \\
Abrasive stone Dimensions & $6 \times 6 \times 70$ & $6 x 6 x 70$ & $6 x 6 x 70$ \\
$(m m x$ mm $x$ mm) & & &
\end{tabular}

Surface topography measurements. First, the honed crankcases were cut in order to extract portions of honed bores and to facilitate optical measurements. A three-dimensional analysis was then undertaken in the mid-height of liner samples. Measurements were performed in three 
locations by a three-dimensional white light interferometer, WYKO 3300 NT (WLI). The surface was sampled at $640 x 480$ points with the same step scale of $1.94 \mu \mathrm{m}$ in the $-\mathrm{x}$ and $-\mathrm{y}$ directions. The form component is removed from acquired 3D data using least square method based on a cubic Spline function. Examples of 3D measured surfaces after the third honing stage generating $130^{\circ}$ cross-hatched grooves using hydraulic and mechanical expansion modes are shown in Fig. 2. $\theta_{1}$ and $\theta_{2}$ represent groove cross-hatch angles obtained after the second and third honing stages respectively.

Furthermore, a morphological decomposition method to extract valley depth (Svq) is used on the 3D measured surfaces as described in [6], [11]. The size of generated grooves (width and depth) is also evaluated from 3D measurements in order to compare the impact of finish, plateau and superfinish stages on the surface topography.

In order to focus only on the effect of groove size on functionality, the three dimensional topography of each surface was scaled numerically at a similar mean roughness Sa (ISO 25178-2 standard) using the same method as described in [5]. In order to obtain a Sa roughness equal to $1 \mu \mathrm{m}$ the following formula is used:

$$
Z_{f}(x, y)=\frac{Z_{i}(x, y) \times 1.0 \times 10^{-6}}{S a_{i}}
$$

Where $Z_{f}$ is the topography of the surface (with $\mathrm{Sa}=1 \mu \mathrm{m}$ ), $Z_{i}$ the topography of the initial surface and $S a_{i}$ the mean initial roughness.

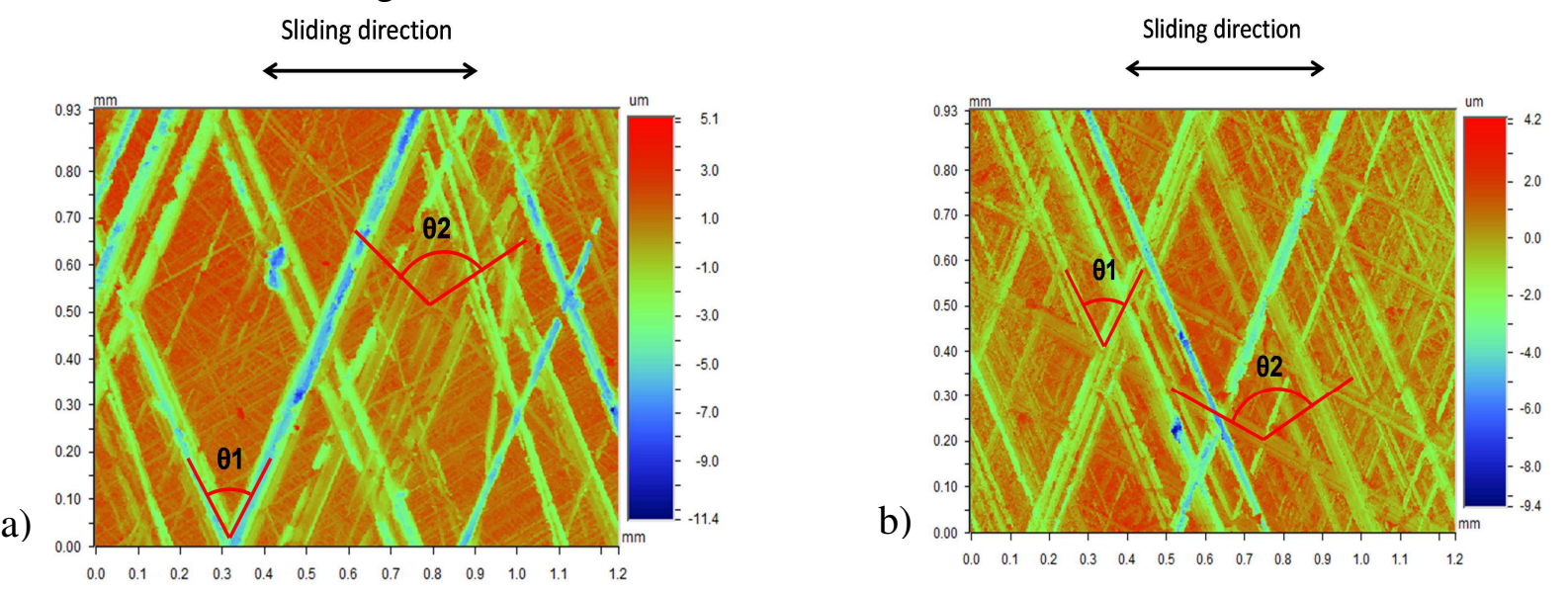

Fig. 2. Topography of a honed surface with $130^{\circ}$ cross-hatched grooves (a) generated after a hydraulic expansion (plateau) and (b) after a mechanical expansion (super-finish).

\section{Numerical model}

A deterministic model has been used to predict frictional performances of each type of honed surface in the mixed lubrication regime.

Elastohydrodynamic equation. The Reynolds' equation has been used to estimate the pressure distribution, $P$, film thickness, $H$, and the friction coefficient, $\mu_{f}$, considering the non-Newtonian behaviour of the fluid.

The equation in dimensionless form is given by:

$$
\frac{\partial}{\partial X}\left(\frac{\bar{\rho} H^{3}}{\lambda \overline{\eta_{X}}} \frac{\partial P}{\partial X}\right)+\frac{\partial}{\partial Y}\left(\frac{\bar{\rho} H^{3}}{\lambda \overline{\eta_{Y}}} \frac{\partial P}{\partial Y}\right)=\frac{\partial \bar{\rho} H}{\partial X}
$$


Where $\lambda=\frac{12 \mu_{0} \times a \times U_{m}}{h_{0}^{2} \times p_{h}}, \overline{\eta_{X}}$ and $\overline{\eta_{Y}}$ are the effective viscosities in the $\mathrm{x}$ and directions respectively according to the Eyring model [12], $a$ the contact radius (m), $\mu_{0}$ the ambient temperature zero-pressure viscosity (Pa.s) and $h_{0}$ is the film thickness constant parameter $(\mathrm{m})$.

The boundary condition $\mathrm{P}=0$ and the cavitation $\mathrm{P}(\mathrm{X}, \mathrm{Y}) \geq 0 \forall \mathrm{X}, \mathrm{Y}$ must be satisfied during the simulation

The lubricant's viscosity and density are chosen to depend on pressure following the Dowson and Higginson formula [13] and Roelands law [14].

The considered ring is a wiper ring, which the bottom part, in the contact zone, is cylindrical with a high radius of curvature.

The film thickness equation is given in dimensionless form by the following equation (parabolic approximtion):

$$
H(X, Y)=H_{0}+\frac{X^{2}}{2} \times\left(\frac{a^{2}}{h_{0} R_{x}}\right)+\bar{\delta}(X, Y)-\overline{Z_{h}}(X, Y)
$$

Where, $Z_{h}$ is the height surface topography at each position $(\mathrm{X}, \mathrm{Y}), R_{x}$ the ring radius of curvature and $\bar{\delta}(X, Y)$ the elastic displacement of the two contact bodies in the normal direction. The elastic deformation is mainly due to roughness that generates pressure peaks in the oil film [15]. The unknown constant $H_{0}$ in the $\Omega_{C}$ domain is determined by the force balance equation:

$$
\frac{w \times L y_{1 p}}{p_{h} \times a^{2}}=\iint_{\Omega_{C}} P(X, Y) d X d Y
$$

Where $w$ is the load per unit length $(\mathrm{N} / \mathrm{mm})$ and $L y_{1 p}$ the real contact length $(\mathrm{mm})$.

Numerical analysis. The Reynolds equation was solved by the finite difference method in order to obtain the film pressure distribution. The solution domain was determined as $-3 \leq \mathrm{X} \leq 3$ and $-4.5 \leq \mathrm{Y} \leq 4.5$. The computational grid covering the domain consisted of equally spaced $512 \times 512$ nodes. For more precision and validation, the reader can refer to the model described in [16].

The applied load $w$ per unit length is equal to $200 \mathrm{~N} / \mathrm{mm}$. The sliding speed is equal to $0.05 \mathrm{~m} . \mathrm{s}^{-1}$. The total friction $\mu_{\mathrm{f}}$ in mixed lubrication regime is evaluated by summing up the boundary friction contributed by the contacted areas and the traction in the hydrodynamic regions:

$$
\mu_{f}=\frac{\iint_{\Omega_{C}} \tau_{c} d x d y+\iint_{\Omega_{C}} \tau_{e} d x d y}{w \times L y_{1 p}}
$$

where $\tau_{\mathrm{c}}$ is the shear stress between the contacting asperities at contact zone $\Omega_{\mathrm{c}}$ and $\tau_{\mathrm{e}}$ is the shear stress of hydrodynamic films within the lubricated zone $\Omega_{\mathrm{c}} . \tau_{\mathrm{e}}$ is calculated at each iteration. $\tau_{\mathrm{c}}$ is considered to be the shear stress of the boundary film which occurs when the local film thickness is less than $1 \mathrm{~nm}$ in the present study. $1 \mathrm{~nm}$ corresponds to the magnitude of a lubricant molecule, which is considered as negligible to generate hydrodynamic pressure flow, according to [17] and [18]. Hence $\tau_{\mathrm{c}}$ can be determined by the Rabinowicz formula [19]:

$$
\tau_{c}=\sqrt{\tau_{s 0}^{2}+\left(\gamma_{s} p\right)^{2}}
$$


Where, $\tau \mathrm{s} 0$ is the initial shear strength of the boundary film and $\gamma_{\mathrm{s}}$ is the pressure coefficient corresponding to the friction coefficient in boundary lubrication. In the present study $\gamma_{\mathrm{s}}$ and $\tau_{\mathrm{s} 0}$ are equal to 0.15 and $2 \mathrm{MPa}$, respectively. $\gamma_{\mathrm{s}}$ is determined experimentally, trough tribometer tests and $\tau_{\mathrm{s} 0}$ is from literature [20].

\section{Results}

From three-dimensional measurement, the valley root mean square height (Svq) was evaluated using the morphological decomposition (Fig. 3). It showed that the global valley depth is sensibly similar between surfaces from the two honing processes, the plateau process (hydraulic expansion at the third stage) and the double finish process (mechanical expansion at the third stage). Nevertheless, the global valley depth is quite higher for surfaces obtained by plateau process for some cross-hatch angles $\left(50\right.$ and $\left.110^{\circ}\right)$.

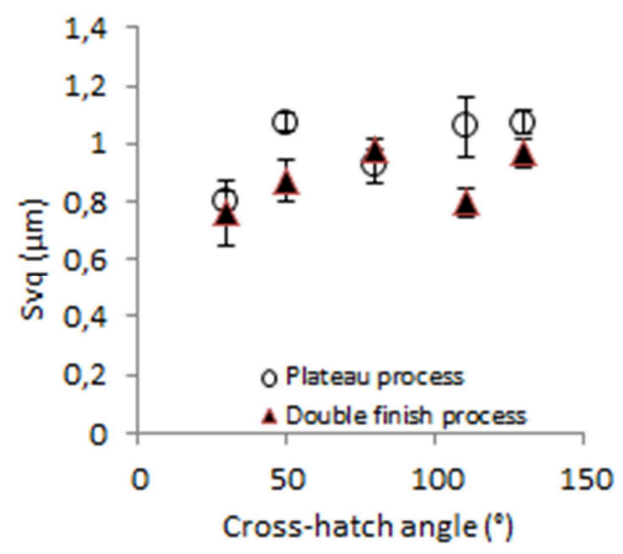

Fig. 3. Evolution of Svq parameter with cross-hatch angle for surfaces generated with plateau process and double finish process.

In order to evaluate the influence of grooves generated during the second and the third honing stages, the valley size (depth and width) of grooves from each honing stage was evaluated directly using 3D measurement.

The size of grooves generated during the second stage (Fig. 4) is very similar for both double finish and plateau processes.
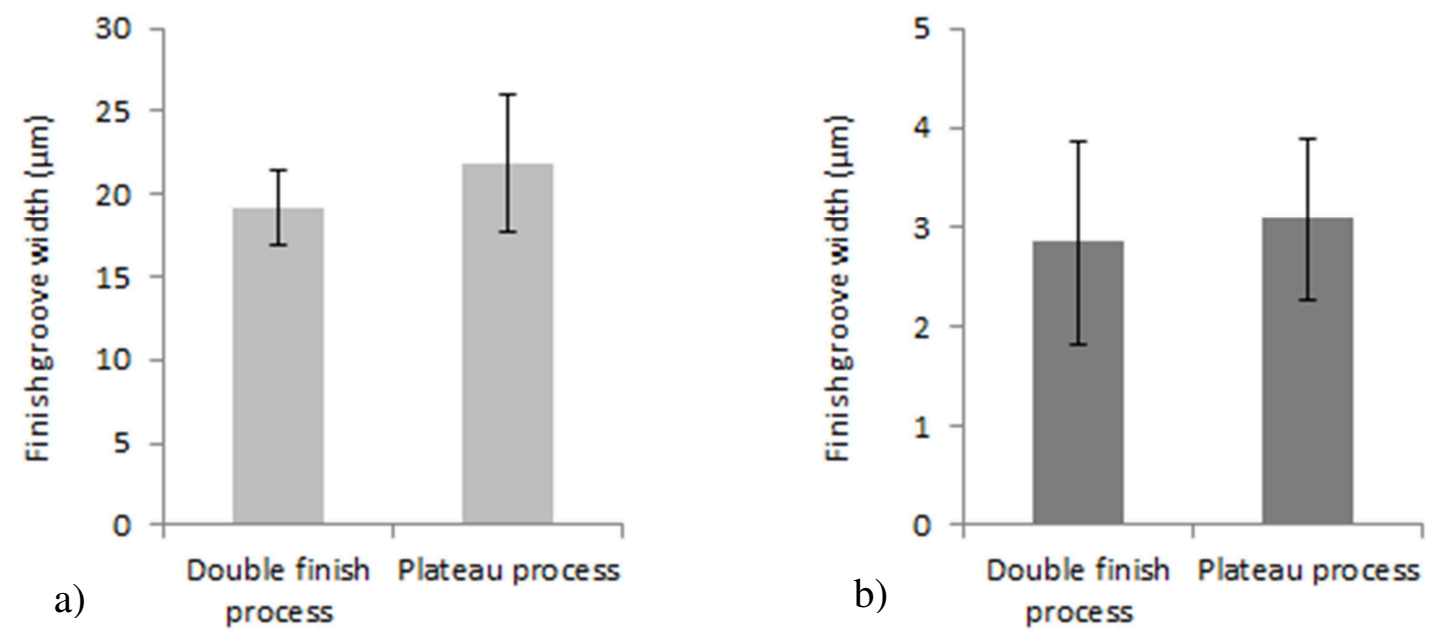

Fig. 4. (a) Valley width and (b) valley depth for grooves generated during the second honing stage (finish stage) after plateau process and double finish process. 
Concerning the grooves generated during the third honing stage, a significant difference is noticed between plateau stage (plateau process) and super-finish (double finish process) groove size (Fig. 5). Super-finish stage grooves are deeper than plateau stage groove especially for a cross-hatch angle $\theta_{2}$ equal to 50, 110 and $130^{\circ}$ (Fig. 5a). The same remarks are applicable for groove depth/width ratio behaviour (Fig. 5b). From these results, because of the similarities of finish grooves, the main differences of the generated surfaces are due to the third honing stage (plateau stage and/or super-finish stage).
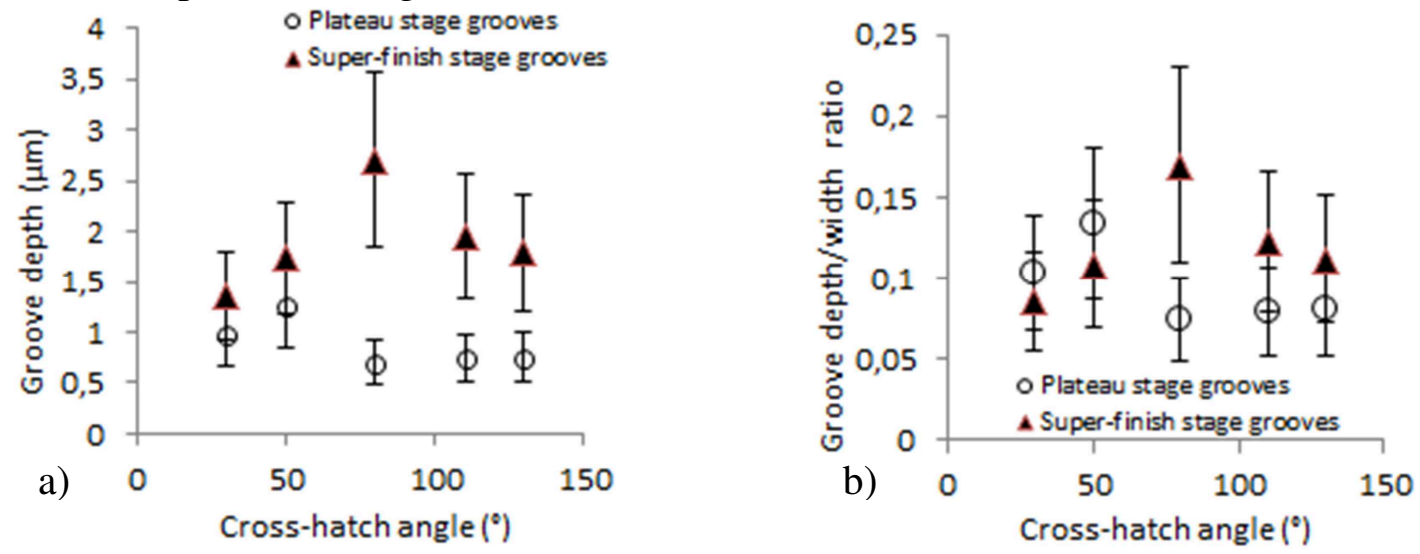

Fig. 5. (a) Depth and (b) depth/width ratio for grooves generated during the third honing stage.

Afterwards, the numerical model described in Section 3 was used to establish a correlation between the generated groove size during the third honing stage and frictional performances.

Fig. 6 represents the mutual effect of cross hatch angle and groove depth on the predicted friction in the ring-liner-piston contact. The amplitude of friction coefficients is in the range [0.04-0.085], which correspond to the mixed lubrication regime. It shows that the friction coefficient decreases mainly with groove depth reduction. However, the lowest $\left[30-40^{\circ}\right]$ and highest $\left[120-130^{\circ}\right]$ crosshatch contribute the most to improve frictional performances. An angle equal to $130^{\circ}$ combined with a groove depth in the range [0.8-1.8], which is the widest, allows to obtain the best frictional surface behavior.

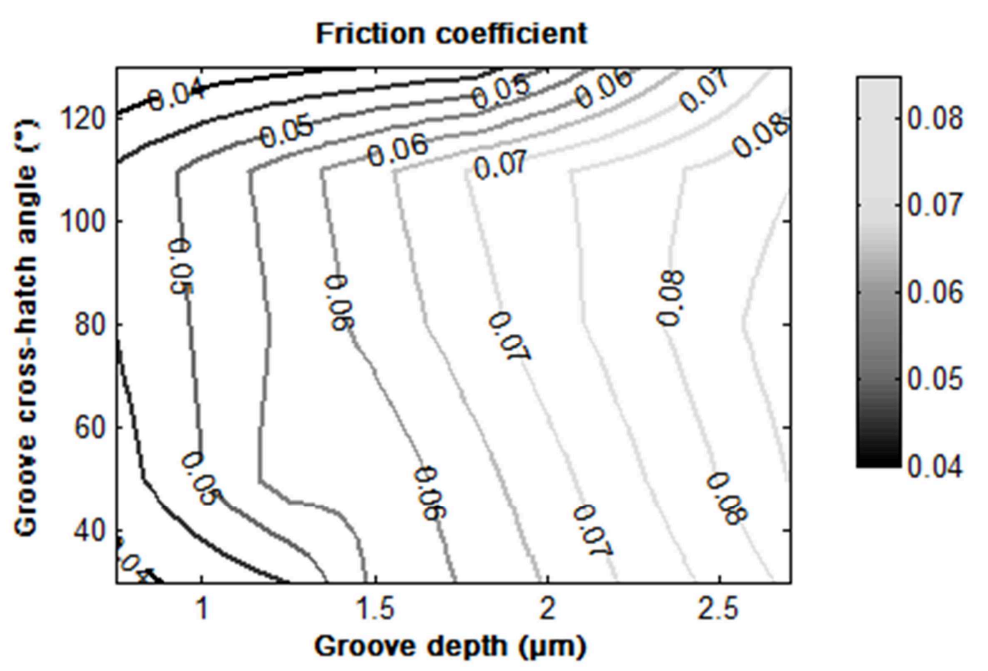

Fig. 6. Predicted friction coefficient vs depth and gross hatch-angle of grooves generated during the third honing stage. 
Fig. 7 represents the mutual effect of cross hatch angle and groove depth/width ratio on the predicted friction in the ring-liner-piston contact. It shows that the friction coefficient decreases mainly with the decrease of groove depth/width ratio. Here the lowest friction coefficients are obtained with surfaces that consist of $\left[120-130^{\circ}\right]$ and $\left[50-60^{\circ}\right]$ groove cross-hatch angles combined with a depth/ratio depth lower than $11 \%$ or equal to $8 \%$ respectively.

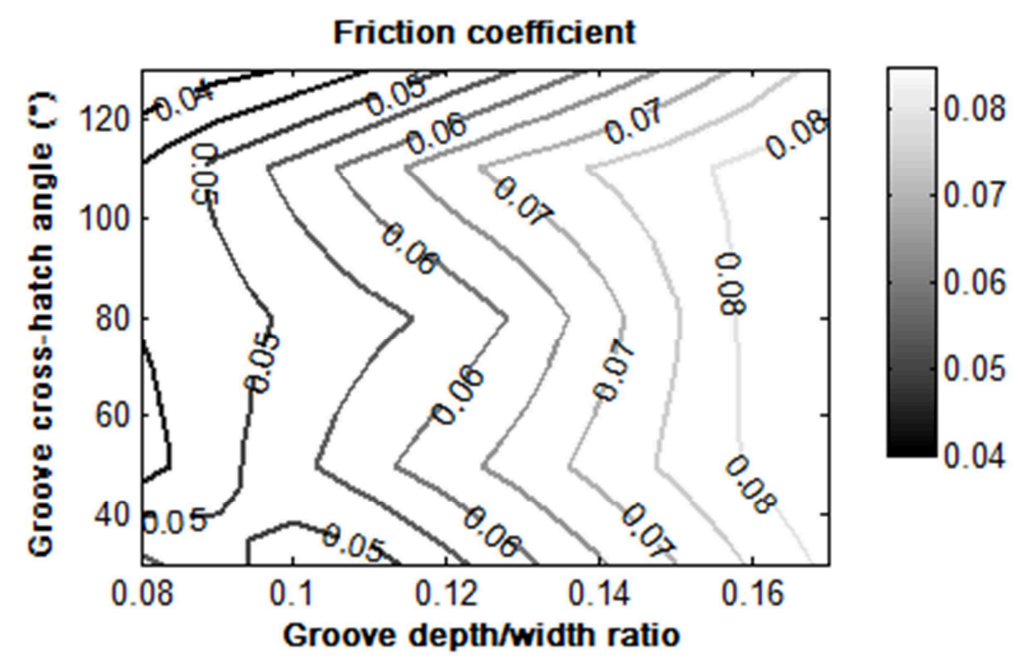

Fig. 7. Predicted friction coefficient vs depth/width ratio and gross hatch-angle of grooves generated during the third honing stage. 


\section{Conclusion}

Grooves generated during the third honing stage influence a lot on frictional performances of honed surfaces in mixed lubrication regime. This study demonstrated the mutual effect of size and crosshatch angle of this type of grooves on the predicted friction coefficient in the ring-piston-liner contact.

Finally results from friction numerical analysis show that:

Both groove depth and depth/width ratio allow to reduce the most significantly friction coefficient. Grooves with a depth lower than $1 \mu \mathrm{m}$ and a depth/width ratio lower than $10 \%$ contribute to obtain the lowest friction coefficient.

Cross-hatch angle allows reducing friction coefficient in the range [120-130 ${ }^{\circ}$. For this range, higher depth (up to $1.8 \mu \mathrm{m}$ ) and depth/width ratio (up to $12 \%$ ) values can be used to obtain the lowest friction coefficients.

\section{References}

[1] D.K. Srivastava, A.K. Agarwal, J. Kumar, Effect of liner surface properties on wear and friction in a non-firing engine simulator, Mater. Des. 28 (2007) 1632-1640.

[2] E. Tomanik, Friction and wear bench tests of different engine liner surface finishes, Tribol. Int. 41 (2008) 1032-1038.

[3] S. Mezghani, I. Demirci, M. El Mansori, H. Zahouani, Energy efficiency optimization of engine by frictional reduction of functional surfaces of cylinder ring-pack system, Tribol. Int. 59 (2013) 240-247.

[4] J. Schmid, T. Hoen, W. Stumpf, Less Wear and Oil Consumption through Helical Slide Honing of Engines by Deutz , 70 (2009) 46-51.

[5] S. Mezghani, I. Demirci, M. Yousfi, M. El Mansori, Mutual influence of crosshatch angle and superficial roughness of honed surfaces on friction in ring-pack tribo-system, Tribol. Int. 66 (2013) $54-59$.

[6] S. Mezghani, I. Demirci, M. Yousfi, M. El Mansori, Running-in wear modeling of honed surface for combustion engine cylinderliners, Wear. 302 (2013) 1360-1369.

[7] Y. Zhou, H. Zhu, W. Tang, C. Ma, W. Zhang, Development of the theoretical model for the optimal design of surface texturing on cylinder liner, Tribol. Int. 52 (2012) 1-6.

[8] C. Ma, H. Zhu, An optimum design model for textured surface with elliptical-shape dimples under hydrodynamic lubrication, Tribol. Int. 44 (2011) 987-995.

[9] C. Caciu, E. Decencière, D. Jeulin, Parametric Optimization of Periodic Textured Surfaces for Friction Reduction in Combustion Engines, Tribol. Trans. 51 (2008) 533-541.

[10] S. Mezghani, I. Demirci, H. Zahouani, M. El Mansori, The effect of groove texture patterns on piston-ring pack friction, Precis. Eng. 36 (2012) 210-217.

[11]E. Decencière, D. Jeulin, Morphological decomposition of the surface topography of an internal combustion engine cylinder to characterize wear, Wear. 249 (2001) 482-488.

[12] P. Ehret, D. Dowson, C.M. Taylor, On lubricant transport conditions in elastohydrodynamic conjunctions, Proc. R. Soc. A Math. Phys. Eng. Sci. 454 (1998) 763-787.

[13]D. Dowson, G.R. Higginson, Elastohydrodynamic Lubrication, the Fundamentals of Roller and Gear Lubrication, Pergamon, Oxford, 1966.

[14]C.J.A. Roelands, Correlational Aspects of the Viscosity-temperature-pressure Relationship of Lubricating Oils, Technical University Delft, Netherlands, 1966. 
[15]N. Ren, D. Zhu, W.W. Chen, Y. Liu, Q.J. Wang, A Three-Dimensional Deterministic Model for Rough Surface Line-Contact EHL Problems, J. Tribol. 131 (2009) 011501.

[16]I. Demirci, S. Mezghani, M. Yousfi, M. El Mansori, Multiscale Analysis of the Roughness Effect on Lubricated Rough Contact, J. Tribol. 136 (2013) 011501.

[17] Y. Hu, D. Zhu, A Full Numerical Solution to the Mixed Lubrication in Point Contacts, 122 (2000) 1-9.

[18] Q.J. Wang, D. Zhu, Virtual Texturing: Modeling the Performance of Lubricated Contacts of Engineered Surfaces, J. Tribol. 127 (2005) 722.

[19]E. Rabinowicz, Friction - especially low friction., MIT Press, 1980.

[20] W. Wang, S. Wang, F. Shi, Y. Wang, H. Chen, H. Wang, et al., Simulations and Measurements of Sliding Friction Between Rough Surfaces in Point Contacts: From EHL to Boundary Lubrication, J. Tribol. 129 (2007) 495. 